\title{
A PETROBRAS NA NOVA CONFIGURAÇÃO ENERGÉTICA GLOBAL
}

\author{
Mônica Sampaio Machado \\ Doutora em Geografia \\ Profa. da Universidade do Estado do Rio de Janeiro \\ monicasampaio@oi.com.br \\ Ciro Marques Reis \\ Mestre em História Universidade do Estado do Rio de Janeiro \\ ciro.reis@gmail.com
}

\begin{abstract}
RESUMO
A brasileira Petrobras integra na atualidade o seleto grupo de global players, participando ativamente da nova configuração energética global em virtude das atividades advindas direta ou indiretamente da exploração e produção do petróleo. Esta nova configuração energética tem modificado radicalmente a estrutura da indústria de petróleo, o ambiente de negócios, e principalmente, elevado os níveis de investimentos, demonstrando a centralidade do petróleo como fonte de movimentação do atual estágio da economia mundial. Buscando analisar a atuação da estatal neste contexto, este artigo procura focalizar a Petrobras no Brasil e na América do Sul. São apresentadas considerações sobre a história e atuação da Petrobras, assim como seu desempenho no Brasil e sua centralidade no continente sul-americano, principalmente com o advento do pré-sal.
\end{abstract}

Palavras-chave: Petrobras, Brasil, América do Sul, Globalização, Geografia

\begin{abstract}
The Brazilian oil company Petrobras today is part of a select group of global players, actively participating in the new global energy configuration. Consequence of the growth in it's exploration and oil production. This new power configuration has radically changed the structure of the oil industry, the business environment, especially, raising investment levels, demonstrating the centrality of oil as responsible for moving the world economy. Analyzing the performance of state-owned company in this context, this article seeks to focus in the activities of Petrobras in Brazil and in South America. Has been presented the history and activities of Petrobras, the performance in Brazil, and the centrality of the company in the South American continent, especially with the advent of pre-salt
\end{abstract}

Keywords: Petrobras, Brazil, South America, Globalization, Geography. 


\section{Introdução}

Após o fim da Segunda-Guerra Mundial sete grandes empresas petrolíferas dominavam o mercado internacional, ditando suas regras, e reproduzindo, de certa maneira, o novo quadro de poder com a consolidação dos EUA como principal ator global. Standard Oil of New Jersey, Standard Oil Company of New York, Standard Oil of California, Gulf Oil, Texaco, Real Dutch Shell, Anglo-Persian Oil Company. Estas companhias ficaram conhecidas como as ñSeven Sistersò. No entanto, reconfigurações geopolíticas originárias de um período repleto de movimentos nacionalistas voltados à descolonização na África, no Oriente Médio, e no Mundo Árabe desarticularam a posição privilegiada dessas companhias. No rastro do processo de descolonização, a Conferência de Bagdá (1960) dava origem a OPEC (Organization of the Petroleum Exporting Countries), tendo como países fundadores, Irã, Iraque, Kwait, Arabia Saudita e Venezuela. Ingressaram posteriormente Qatar, Indonésia (saiu em 2009), Líbia, Emirados Árabes, Argélia, Nigéria, Equador (suspenso em 1992), Angola, Gabão (entre 1974 e 1994). A OPEC passava gradualmente a controlar o mercado, com potencial de influenciar a regulação da produção e do preço do barril de petróleo, diminuindo assim, a influência dessas companhias privadas ${ }^{1}$.

Após cinco décadas de adaptações às transformações geopolíticas, das ñseven sistersò originais, permaneceram aquelas que são consideradas suas descendentes, as quatro ñSuper Majorsò British Petroleum, Chevron, ExxoMobil e Royal Dutch Shell, que atuam fortemente em todos os continentes e ramos da indústria do petróleo. No entanto, este grupo passou a ter companhia. Empresas estatais de petróleo, especialmente oriundas de países em desenvolvimento, passaram a figurar de forma importante no cenário mundial: As ñNew Seven Sistersò Saudi Aramco (Arábia Saudita), Gazprom (Rússia), CNPC (China), NIOC (Iran), PDVSA (Venezuela), Petrobras (Brasil) e Petronas (Malasia). A metodologia utilizada para classificar essas empresas considerou o tamanho dos recursos disponíveis, o tamanho da produção, o nível de ambição da empresa, a influência de suas ações sobre outras empresas, e o tamanho do seu mercado doméstico. Outro elemento chave neste processo é a presença do Estado como indutor do crescimento dessas empresas (Hoyos, 2007). 
Embora a instabilidade do Oriente Médio e do Mundo Árabe seja uma constante, recentemente reafirmada pela serie de eventos designados de ñPrimavera Árabeò em 2011, pela crescente tensão entre o Irã e os EUA, e pelo histórico interesse imperialista desses últimos nessa região (Harvey, 2005), o quadro atual apresenta uma novidade: o crescimento econômico dos países de industrialização tardia, e a consequente participação de suas empresas estatais de petróleo nos negócios regionais e globais. Esta nova configuração energética global transforma a estrutura da indústria de petróleo, o ambiente de negócios, e principalmente, eleva os níveis de investimentos. As NOCs (national oil companies) passaram a desempenhar um papel importante no mercado global de energia. Na segunda metade da década de 2000, as NOCS já detinham aproximadamente $65 \%$ das reservas mundiais de petróleo e gás, e produziam cerca de $57 \%$ do petróleo mundial e eram responsáveis por $38 \%$ da produção de gás. Por outro lado, as IOCs (international oil companies) procuraram expandir suas atividades em todo o mundo através de fusões e aquisições (Al-Naimi, 2006). Estima-se que nos próximos 40 anos as NOCs sejam responsáveis por $90 \%$ das reservas mundiais. As IOCs sustentam sua competitividade através da venda de produtos de maior valor agregado, como gasolina, diesel, e principalmente petroquímicos (Hoyos, 2007).

A brasileira Petrobras integra um seleto grupo de global players, e atua na indústria mais estratégica do planeta. O produto petróleo é a riqueza mais fundamental do sistema capitalista, emprestando às grandes corporações do ramo, mais peso e influência do que maioria dos Estados nacionais do mundo. Piquet \& Serra (2007) definem com clareza o valor estratégico do petróleo e o seu poder transformador do espaço.

O petróleo apresenta ainda outras especificidades: trata-se de recurso nãorenovável, altamente estratégico e sua exploração envolve o domínio de tecnologia de ponta. As corporações que operam no setor atuam de modo globalizado, organizando o espaço de maneira seletiva e extrovertida. As áreas produtoras funcionam como campos de fluxos, onde se articulam sofisticadas redes de unidades industriais, postos, dutos, aeroportos, bens, homens e informaçães. [...] a produção de petróleo [...] é objeto de acirradas disputas no plano internacional. O domínio e/ou a posse das jazidas tornou-se até mesmo ñuma fonte renovável de guerrasò. (p.22)

As descobertas e especulações de novos poços de petróleo e gás natural na camada pré-sal a partir de 2007, no território brasileiro marítimo, são grandes 
responsáveis por uma nova dinâmica econômica doméstica, regional e global. Encabeçando esta nova dinâmica está a Petrobras. A empresa nacional Petrobras comanda o ramo de petróleo e gás não apenas no Brasil, mas na América Latina. Sociedade anônima de capital aberto, com $48 \%$ do controle do governo brasileiro, seu sócio majoritário, a Petrobras além de líder no setor energético latino-americano é a $3^{\text {a }}$ maior empresa do mundo na atualidade. O desempenho da Petrobras, nesse sentido, parece cada vez mais estar associado ao desempenho da economia brasileira. Este trabalho resulta, assim, da intenção em acompanhar mais de perto as atividades da Petrobras como uma chave de leitura do atual desenvolvimento brasileiro e da integração sul-americana.

Com base em dados levantados e sistematizados pelo Grupo de Pesquisa GeoBrasil (UERJ) este artigo focaliza a Petrobras no Brasil e na América do Sul. São apresentadas considerações sobre a história e atuação da Petrobras, assim como seu desempenho no Brasil e sua centralidade no continente sul-americano, principalmente com o advento do pré-sal.

\section{Petrobrás: criação e expansão}

A Petrobras, Petróleo Brasileiro S/A, foi criada em 03 de outubro de 1953, por Getúlio Vargas, quando assinou a Lei 2004 estabelecendo o monopólio estatal de petróleo sobre a pesquisa e exploração das reservas de petróleo e de gás natural, assim como sobre o refino e o transporte, fruto e uma intensa campanha lançada em 1946, o petróleo é nosso. A empresa era, então, o instrumento do Estado brasileiro, para o exercício desse monopólio, tendo sido estendido às atividades de exportação e importação de hidrocarbonetos, em 1963. (Fuser, 2007)

A criação da Petrobrás também era uma questão de soberania nacional. $O$ ambiente nacional estava impregnado de discussões voltadas ao nacionalismo, à defesa nacional, e à necessidade de desenvolvimento e industrialização do país (Penna, 2005; Baer, 2002). Além da criação de uma identidade nacional através da independência energética, o nascimento de corporações estratégicas ao desenvolvimento e soberania nacionais acaba por criar ñuma identidade empresarial estatalò, até hoje visível na Petrobrás. (Deslandes, 2011).

Geo UERJ - Ano 13, nº 22, v. 2, $2^{\circ}$ semestre de 2011 p. 362-378 - ISSN 1981-9021 http://www.e-publicacoes.uerj.br/index.php/geouerj 
A expansão internacional ocorreu na década de 70, quando em 1972 foi criada a Braspetro, seu então braço internacional. Nas décadas de 70 e 80 , as atividades da Petrobrás/Braspetro no exterior eram basicamente relacionadas à compra e venda de petróleo e prestação de serviços de perfuração de poços.

A partir de meados dos anos 80, a Petrobras concentrou atividades na América do Sul, Colômbia (1985), Equador (1987) e Argentina (1989). Entretanto, entre 1989 e 1995, a empresa parou sua expansão para o exterior, sendo apenas retomada, em 1997, com a quebra do monopólio estatal, no então governo Fernando Henrique Cardoso, que propiciou sua privatização parcial, com a abertura do seu capital aos investimentos privados, a partir de 2000.

A retomada da estratégia internacional da Petrobras tem, contudo, início em 1994, momento em que se intensificou o processo de integração econômica dentro do Mercosul e os acordos de cooperação com a Bolívia e o Chile. A Petrobras decidiu, assim, direcionar sua expansão para a América do Sul, em todos os segmentos de atividades, buscando aproveitar a proximidade do mercado brasileiro e as vantagens dos acordos comerciais existentes. E em 1996, passou então a explorar jazidas de gás na Bolívia. Hoje a Petrobras é uma sociedade anônima de capital aberto, cujo acionista majoritário é o governo brasileiro, isto é, uma empresa estatal de economia mista, controlada pela União. O Estado brasileiro detém a maioria absoluta das ações ordinárias, que dão direito de voto nas decisões da empresa, e é o presidente da República quem nomeia os seus principais dirigentes. Mas a Petrobras é também uma empresa privada, na medida em que grande parte do seu capital está em mãos de investidores privados. Sena Filho (2004) já destaca a importância alcançada pela Petrobras em tempos de globalização, e sua íntima relação com Estado:

ñNeste novo mundo que se configura, tecnologia de ponta (em todos os setores da economia) e expansão de empresas com auto grau de tecnologia parecem ser dois condicionantes, tanto para a sobrevivência dessas empresas quanto para o fortalecimento dos estados nacionais que as gerem. Nesse sentido, a Petrobrás aparece como uma empresa altamente estratégica [...] Sendo ao mesmo tempo corporação e pertencendo a um Estado soberano, a Petrobrás pode, ao aliar uma grande competitividade com projetos sociais, servir de modelo para futuros projetos desenvolvimentistas.ò(p.85) 
Sediada no Rio de Janeiro e operando atualmente em todos os continentes, a Petrobras na atualidade exerce atividades no seguimento de energia, nos setores de exploração e produção, refino, comercialização e transporte de óleo e gás natural, petroquímica, distribuição de derivados, energia elétrica, biocombustíveis e outras fontes renováveis de energia. No exterior a Petrobras, que predominantemente atuava na exploração e produção, passou recentemente a atuar também na área de downstream, ou seja, nas áreas de negócio que lidam com o refino, distribuição e venda de produtos petrolíferos, abrange, assim, desde as áreas de produção até o produto final.

A Petrobrás desenvolve atividades por meio de unidades, empresas subsidiárias e representações comerciais e financeiras em 28 países. Sua maior área de influência é o continente americano, com atuações em 13 países. Na América do Sul a Petrobras atua em 10 países, incluindo o Brasil (exploração e produção, transporte por dutos, comercialização, distribuição, gás e energia, refino, petroquímica e fertilizantes, e energia elétrica, serviços), Argentina (exploração e produção, transporte por dutos, comercialização, distribuição, gás e energia, refino, petroquímica e energia elétrica), Bolívia (exploração e produção, transporte por dutos, gás e energia) Chile (downstream), Colômbia (exploração e produção), Equador (exploração e produção), Paraguai (distribuição), Peru (exploração e produção), Uruguai (distribuição de gás natural e transporte por dutos) e Venezuela (exploração e produção). Na América Central a Petrobrás atua em Cuba, com atividades de exploração e produção. Na América do Norte, nos Estados Unidos (exploração, produção e refino) e no México (exploração e produção).

\section{Os desafios do pré-sal}

A expansão da Petrobras no Brasil e no mundo toma grande impulso com anúncio de indícios de megareservas do pré-sal, em 2007. De lá para cá a Petrobras deixou de ser uma empresa de pequeno porte para tornar-se uma das maiores promessas de produção e exportação do mundo. O tamanho do desafio do pré-sal foi exposto por Gabrieli de Azevedo (2009):

A escala da demanda brasileira é de um tamanho tal que pode atrair vários nichos de mercado para implantar aqui a capacidade adicional produtiva mundial de vários equipamentos e de fornecimento de serviços, que terá de 
ocorrer para atender a essa demanda. O volume de sondas de perfuração de alta profundidade, centenas de barcos de apoio e navios transportadores, os milhares de quilômetros de tubulações, centenas de válvulas, compressores, máquinas, torres, e as dezenas de unidades de produção são alguns dos exemplos de compras necessárias para viabilizar os investimentos no desenvolvimento da produção do pré-sal e das outras áreas de exploração e produção da Petrobrás e seus sócios. São investimentos que fundamentam a viabilidade da criação de um enorme impacto multisetorial da expansão da cadeia. (p. 262)

A descoberta do reservatório Tupi, na Bacia de Santos, que parece ser apenas a ponta de um iceberg sob uma espessa camada de sal, que se estende a cerca de 300 quilômetros, do litoral de Santa Catarina até o norte do Espírito Santo, pode elevar o Brasil da atual $17^{a}$ posição no ranking das maiores reservas de petróleo do mundo para algo entre os cinco primeiros da lista. Essas reservas promoveram mudança da legislação brasileira para a exploração de novas áreas. Em vez do sistema de concessão, quer tornar a Petrobras a principal operadora das novas áreas, que serão exploradas por companhias privadas, por meio do sistema de partilha, ou seja, em que o governo federal continua proprietário das reservas e é quem define, em última instância, o que fazer delas e o ritmo de desenvolvimento. (Revista América Econômica, 500 Maiores Empresas da América Latina, julho 2010). Segundo o diretor da área internacional da Petrobrás, Jorge Zelada (2009), com o advento do pré-sal em um futuro próximo o Brasil terá um excesso de produção ou, com os investimentos de refino que estão sendo feitos no Brasil, um excesso de produtos derivados, que o colocarão como importante exportador desses produtos. E se há excedente de produção é necessária uma colocação no mercado para esses produtos. Fatalmente vai haver uma maior participação dos seguimentos de refino, distribuição e de gás no lugar de exploração e produção. Com aumento estimado para a produção nacional e os investimentos feitos no refino no Brasil a empresa já se enverga com potencial exportadora de derivados dentro de alguns $\operatorname{anos}^{2}$. Todo esse dinamismo vinculado ao petróleo pode ser sentido ao se analisar a complexa e atual rede de produção e serviços da Petrobras, que tem propiciado inúmeros empregos diretos e indiretos, dinamizando lugares, cidades e municípios brasileiros, assim como vários países sul-americanos. Vale destacar suas principais subsidiárias e atuações no Brasil e no mundo. 


\section{Principais subsidiárias da Petrobras}

\begin{tabular}{|c|c|l|}
\hline Petroquisa & $\begin{array}{c}\text { Petrobrás Química } \\
\text { S.A. }\end{array}$ & $\begin{array}{l}\text { Vem diversificando os produtos derivados do petróleo, como a parafina } \\
\text { e nafta, presentes em diversos produtos, como batom, chiclete, tintas, } \\
\text { resinas, velas, cera, embalagens, impermeabilizantes, tecidos, fósforos, } \\
\text { etc }\end{array}$ \\
\hline $\begin{array}{c}\text { Petrobras } \\
\text { Distribuidora }\end{array}$ & $\begin{array}{c}\text { Petrobras } \\
\text { Distribuidora }\end{array}$ & $\begin{array}{l}\text { Líder no mercado brasileiro, além dos postos que atendem o } \\
\text { consumidor final, a empresa tem uma enorme lista de grandes firmas } \\
\text { entre indústrias, termoelétricas, companhias de aviação, frotas de } \\
\text { veículos, etc }\end{array}$ \\
\hline Transpreto & $\begin{array}{l}\text { Petrobras Transporte } \\
\text { S.A. }\end{array}$ & $\begin{array}{l}\text { Atua no transporte e armazenamento de petróleo, derivados, álcool e } \\
\text { mais de 11mil km de oleodutos e gasodutos, além dos transportes } \\
\text { navios petroleiros. Os terminais, que armazenam produtos antes do } \\
\text { envio para as refinarias ou exportação, fazem parte também deste setor. } \\
\text { Os principais produtos comercializados são: diesel, gasolina, gás } \\
\text { liquefeito de petróleo (GLP), nafta, óleo combustível e querosene de } \\
\text { aviação (QAV). }\end{array}$ \\
\hline Petrobras & Petrobras & $\begin{array}{l}\text { A estatal tem igualmente investido em pesquisas por energias } \\
\text { renováveis, principalmente para obtenção do biodiesel e novas técnicas } \\
\text { de produção do etanol. }\end{array}$ \\
\hline Biocombustível & Biocombustível \\
\hline Gaspetro & Petrobras Gás S.A. & $\begin{array}{l}\text { antiga Petrofertil, que atua na produção, comércio, importação, } \\
\text { exportação, armazenagem, transporte e distribuição de gás natural, gás } \\
\text { liquefeito de petróleo e gases raros de quaisquer origens; de } \\
\text { fertilizantes, suas matérias-primas e produtos correlatos; de energia } \\
\text { termoelétrica; de sinais de dados, voz e imagem por meio de sistemas } \\
\text { de comunicação por cabo e rádio; bem como a prestação de serviços } \\
\text { técnicos e administrativos relacionados a tais atividades. }\end{array}$ \\
\hline
\end{tabular}

Fonte: http://www.petrobras.com, consulta 10/10/2011.

Elaboração: GeoBrasil, Grupo de Pesquisa Geografia Brasileira: História e Política (UERJ)

\section{Liderança na América do Sul: a relação com a Bolívia.}

Desde meados da década de 90, com a retomada da expansão internacional da empresa, a Petrobras passaria a intensificar sua atuação na América do Sul, com intuito de se tornar um dos principais atores de petróleo e gás natural no Cone Sul. Do ponto de vista da política internacional do Estado brasileiro, a diplomacia passou a enxergar a Petrobras como uma importante instituição para a integração sul-americana. A integração energética seria, assim, fundamental. Conforme Igor Fuser (2007) naquela época os exemplos mais significativos desse processo foram as aquisições de empresas na Bolívia e na Argentina, especialmente, a construção do Gasoduto Brasil-Bolívia (Gasbol) pela Petrobras entre 1997 e 1999, a partir de um acordo bilateral entre esses dois países. O Plano de Negócios da Petrobras de 2007-2011 deu continuidade e prioridade ao projeto de integração energética latino-americana, apresentando como estratégia corporativa a ampliação das atividades da empresa na América Latina e na América do Sul. Sua principal meta era ñiderar o mercado de petróleo, gás natural, 
derivados e biocombustíveis na América Latina, atuando como empresa integrada de energia, expansão seletiva da petroquímica, da energia renovável e da atividade internacional. Desenvolver e liderar o mercado brasileiro de gás natural e atuar de forma integrada nos mercados de gás e energia elétrica na América do Sul.ở

Com relação ao valor dos investimentos internacionais por regiões, a América do Sul continua sendo a prioritária, com cerca $28 \%$ do total dos recursos, seguida pela América do Norte, com $23 \%$ e a África, com 16\%. Dentre os produtos derivados do petróleo, o gás tem tido participação crescente na matriz energética. Como no Brasil a tendência é aumentar tanto a produção de gás quanto o consumo, o país vai precisar continuar a importação de gás, que atualmente é fornecido pela Bolívia. E, nesse sentido, a Bolívia é estratégica para a matriz energética brasileira. Para dos Santos (2002):

\begin{abstract}
... a Bolívia se transformou em uma grande província gasífera, com enormes possibilidade de integração sinérgica com os mercados brasileiros e bastante isolada do resto do mundo. Trata-se portanto de uma oportunidade histórica para o Brasil e a Bolívia. Para os próximos 50 anos o gás boliviano representa a aposta energética mais competitiva que o Brasil poderá explorar. A consolidação de mercados sustentáveis no lado do Brasil viabilizará a construção das infra-estruturas de integração entre os dois países... (p.259)
\end{abstract}

Entretanto, se o Brasil investir mais expressivamente na produção de gás, talvez possa no futuro tornar-se um exportador. Mas, hoje, o gás que o Brasil consome é em grande parte da Bolívia e dos campos de petróleo da Petrobrás no Brasil. O Brasil consome atualmente 60 milhões de metros cúbicos diários de gás, produz 30, e importa 30. Metade é importada, metade é produzida no país.

No caso boliviano, o país tem atualmente em seus estoques de gás natural seu maior trunfo, já que suas reservas de petróleo ficam bem abaixo das de gás. E como o uso do gás cresceu muito no Brasil nos últimos anos, em função de ser um combustível de qualidade, com alta capacidade energética e nível de poluição mais reduzido, o Brasil tem sido seu principal mercado. Os principais estados onde o gás boliviano é distribuído são: São Paulo, onde cerca de $75 \%$ do consumo é abastecido pelo produto da Bolívia, além de atender integralmente aos estados de Mato Grosso do Sul, Paraná, Santa Catarina e Rio Grande do Sul ${ }^{4}$. O Brasil hoje conta com o maior gasoduto da América Latina, pronto para oferecer às indústrias de cerâmica, vidro, alimentos e bebidas, papel 
e celulose, metalurgia, química, petroquímica e dezenas de outras, um combustível limpo, econômico e livre da necessidade de formação de estoques ${ }^{5}$.

Assim, a presença da Petrobras na Bolívia tem papel relevante na integração dos mercados de gás natural e energia do Cone Sul. Segundo dados veiculados no site da empresa, a Petrobras não apenas possibilitou o aumento em oito vezes das reservas de gás natural do país, como também marcou uma época de desenvolvimento da indústria e da economia bolivianas ${ }^{6}$. A Petrobras Bolívia foi criada em 1995, e em menos de dez anos, tornou-se a maior empresa daquele país. Nesse período, realizou investimentos superiores a US\$ 1,5 bilhão, equivalentes a $18 \%$ do PIB boliviano e recolheu um volume de impostos que corresponde a $25 \%$ da arrecadação tributária do país. As operações da Petrobras Bolívia provocaram um forte impacto na economia local, registrando uma média de US\$ 100 milhões gerados com a aquisição de produtos e serviços de empresas bolivianas. A Petrobras Bolívia e suas subsidiárias respondem pela criação de mais de 1.500 empregos diretos no país, sendo que $95 \%$ de seus funcionários, aproximadamente, são bolivianos ${ }^{7}$. Desde o início das operações (1996), atuou em sociedade com a Yacimientos Petrolíferos Fiscales Bolivianos (YPFB), assinando contrato, em 1992, de compra e venda de gás natural, para participar da exploração e produção de hidrocarbonetos na Bolívia. Ambas as empresas estabeleceram parcerias não apenas para exploração e desenvolvimento de reservas, como também para a construção do gasoduto Bolívia-Brasil, a obra de infra-estrutura de energia mais importante da América Latina ${ }^{8}$. Toda a infra-estrutura construída por essa parceria consolidou o gás como a maior commodity produzida na Bolívia, promovendo desenvolvimento econômico de ambos os países.

Em Hofmeister (2007) fica clara a condição de grande corporação da Petrobras e sua importância regional:

La evolución política interna de este vecino [Bolívia] afecta directamente los intereses brasileños dado que uno de los motivos claves de las protastas en Bolívia tiene que ver con las condiciones de explotación y venta de gas natural. Brasil no solamente es el consumidor más importante del gas boliviano, sino que lá corporación de energia semi-estatal brasileña Petrobras és o principal inversionista en Bolívia propietaria de oleoductos y refinerías; Petrobrás genera aproximadamente de un 15 a un $20 \%$ del PIB boliviano. La crítica de los partidos y movimientos bolivianos sobre empresas internacionales y su revindicación de convertirlas em empresa estatales se refieren, entre otras cosas, a esta corporación brasileña.(p.81) 
E quando Evo Morales decretou a nacionalização dos hidrocarbonetos, em 2006, a centralidade e importância da Petrobras no contexto sul-americano, e especificamente econômico da Bolívia, tornaram-se ainda mais evidentes em todo o mundo.

A Bolívia aparece também como geoestratégica nos projetos e planos para a integração sul-americana elaborados e executados pela Iniciativa para a Integração da Infra-Estrutura Regional Sul Americana (IIRSA), importante organismo de integração regional, criado em Brasília, em 2000, com assinatura de 12 países (Argentina, Bolívia, Brasil, Chile, Colômbia, Equador, Guiana, Paraguai, Peru, Suriname, Uruguai e Venezuela), com investimentos advindos, essencialmente, do Banco Nacional de Desenvolvimento Econômico e Social (BNDES) e do Banco Interamericano de Desenvolvimento (BID). A Bolívia é o único país da América do Sul a fazer parte dos três subsistemas regionais, a Bacia Amazônia, a Bacia Platina e o subsistema do Pacífico, um dos principais eixos de integração sul-americana, que só poderá ser construído com sua inclusão. Para tanto, a atuação e o fortalecimento da Petrobras em território boliviano são fundamentais, não apenas em função da construção da infraestrutura energética, mas também para a implantação de outros projetos, como a construção de eixos rodoviários interoceânicos, de igual interesse dos outros países sulamericanos.

\section{O peso do Brasil e na América do Sul e outras formas de integração regional.}

É inegável a posição de liderança brasileira na América do Sul. Em 2000 o Informe Mercosul 2000-2001 (relatório anual promovido pela INTAL para aprofundamento dos conhecimentos sobre processos de integração regional na América Latina e no Caribe), através de uma análise comparativa demonstrava as discrepâncias entre o Brasil e seus vizinhos em três indicadores. As populações dos parceiros do Mercosul (Argentina, Uruguai e Paraguai) somadas correspondiam a 27\% da população brasileira. Em área correspondem a 39\% da área do Brasil. Em 1998, somados os seus PIBs correspondiam a $44 \%$ do PIB brasileiro 9 .

Em 2010, de acordo com os dados do Banco Mundial, o PIB brasileiro ultrapassou a casa dos 2 trilhões de dólares, enquanto que a soma dos PIBs de seus parceiros do Mercosul não ultrapassou a casa dos 500 bilhões de dólares ${ }^{10}$. A diferença 
populacional também aumentou. Os três parceiros do Brasil no Mercosul somam agora aproximadamente 50 milhões de habitantes, $25 \%$ da população brasileira atual que se aproxima da marca de 200 milhões de habitantes. Não há dúvidas que as dimensões do seu território, repleto de riquezas naturais, e o tamanho de sua economia reservam ao Brasil o lugar de protagonismo na América do Sul, e também na América Latina.

Como um dos maiores países do mundo em extensão territorial, o $4^{\circ} \mathrm{em}$ área contínua, o Brasil ocupa $8.514 .876 \mathrm{~km}^{2}$ do continente sul-americano, ou seja, aproximadamente $47 \%$ de sua área total, sem contar com a plataforma continental, a Amazônia Azul, com cerca de 4,5 milhões de $\mathrm{km}^{2}$, acrescentando ao país uma área equivalente a mais de $50 \%$ de sua extensão. Em termos geoestratégicos, o Brasil desfruta de oportunidades extraordinárias pelas características e dimensões de suas fronteiras que se estendem por 23.086 km: uma faixa litorânea Atlântica de 7.367 km² e uma extensa fronteira territorial de $15.719 \mathrm{~km}$ com dez países, Argentina, Bolívia, Colômbia, Guiana, Paraguai, Peru, Suriname, Uruguai, Venezuela e Guiana Francesa. Apenas Chile e Equador não possuem fronteiras com o Brasil. Já a saída para o Pacífico, um antigo e almejado projeto territorial brasileiro, foi estabelecida ao norte, em julho de 2011, com a conclusão do trecho da rodovia Transoceânica, a ponte sobre o Rio Madre de Dios no Peru, ligando o país, por meio do Acre, Rio Branco, aos portos peruanos, Ilo Matarani e San Juan de Marcona. Em termos de recursos naturais renováveis a água do país e a riqueza da biodiversidade da Amazônia brasileira, 60\% da região amazônica, são seus maiores trunfos. O Brasil possui uma das mais extensas e diversificadas redes fluviais de todo o mundo, com a maior reserva mundial de água doce e o maior potencial hídrico da Terra. A floresta amazônica apresenta uma variedade de sistemas naturais, concentrando cerca de $20 \%$ da biodiversidade do planeta, sem contar com a diversidade cultural dos povos indígenas e comunidades remanescentes de antigos quilombos, seringueiros, castanheiros, ribeirinhos, entre outros.

No plano econômico os benefícios da geografia brasileira residem na ampliação da potencialidade de exploração de sua vasta diversidade de recursos naturais, renováveis e não renováveis. Dentre os recursos não renováveis, o petróleo e o gás natural têm sido commodities de grande relevância no PIB nacional, alavancando uma nova e expressiva rede de produção, serviços e utilização dos lugares. 
Esse protagonismo do Brasil no continente sul-americano estebelece o país como o motor da região. Região esta que serve para o Brasil como base de projeção internacional, com grande importância politica. Porém, o modelo de inserção brasileira na economia mundial tem sido um dilema. Historicamente o Brasil possui uma tradição de relações economicas bilaterais, atuando isoladamente dos seus vizinhos sulamericanos. Por outro lado, vem buscando o fortalecimento dos orgãos de integração regionais como o Mercosul, a Unasul e o IIRSA. Esses dois últimos apontam para a uma diferenciação do modelo de regionalismo voltado apenas para o livre comércio, como o caso do Mercosul, e demarcam um tipo de regionalismo de caráter estrutural, físico entre os países. Para Lima \& Coutinho (2007), ñum modelo estrutural do regionalismoò.

\begin{abstract}
Se o regionalismo aberto da década de 1990 expressava uma idéia de região, como um espaço de fluxo, próximo a definição de espaço virtual com que os ideólogos da globalização escreviam as relações internacionais naquele momento, nos anos 2000 a tônica parece ser a demanda política por regiões que, por sua vez, retornam aos seus contornos geográficos tradicionais em função da confluência de dois processos no sistema internacional e que podem ser sintetizados na idéia de valorização política e física das regiões.(p.132)
\end{abstract}

Mas especificamente sobre a América do Sul e a liderança do Brasil nesse processo:

Os projetos de integração regional nas áreas de infraestrutura e de energia, que recém se iniciaram, criam essas vinculações e interdependências dos diferentes países sul-americanos, aproximando vizinhos ainda distantes entre si. Ao Brasil cabe uma responsabilidade maior na coordenação da ação coletiva regional pelo diferencial de recursos e por ter mais a ganhar com a integração. (p.137)

\title{
Conclusões
}

A atuação da Petrobrás na atualidade tem provocado transformações rápidas e radicais na organização do território brasileiro, se constituindo como uma empresa nodal no desenvolvimento nacional e no setor energético sul-americano. Com amplo potencial inovador, vem implementando processos de alta tecnologia e promovendo, direta ou indiretamente, capacitação de mão de obra altamente especializada e pioneira, como no caso da exploração do pré-sal. Sua íntima relação com Estado brasileiro, numa espécie de relação mutualista, acaba por emprestá-la também um alto grau de Geo UERJ - Ano 13, no. 22, v. 2, 2º semestre de 2011 p. 362-378 - ISSN 1981-9021

http://www.e-publicacoes.uerj.br/index.php/geouerj 
responsabilidade política, social e econômica, não apenas para país, mas para os seus vizinhos da América do Sul, que vivem uma relação de interpendência assimétrica com o grande vizinho.

Grandes desafios esperam o Brasil, como a maior potência da América Latina. Como prover e sustentar uma economia de mercado e os desafios da crise capitalista global e uma distribuição menos desigual da riqueza? Um país que historicamente mantem inalteradas as desigualdades estruturais a despeito das mudanças econômicas e políticas dos últimos anos, conforme dados revelados pelo Instituto de Pesquisa Econômica Aplicada (IPEA) em 2008. Como avaliar a dinâmica econômica brasileira da atualidade e seus impactos? Embora supere seus vizinhos em números absolutos de produção e acumulação de riquezas, o Brasil possui índices que demonstram atrasos sociais e velhos vícios estruturais. De acordo com dados do Banco Mundial referentes ao ano de 2010, o Brasil ainda possui renda bruta nacional per capita (\$10.920) menor do que as rendas de Argentina (\$15.250), Chile (\$13.900), Uruguai (\$13.890), e Venezuela (\$11.950). Mesmo posicionado entre as cinco maiores economias do mundo, o Brasil, no quesito distribuição de riquezas, ainda está muito atrás de países como França (\$34.440), Espanha (\$31.640), Itália (\$31.130), e Portugal (\$24.710).

As recentes iniciativas de integração física no continente sul-americano, consequência da valorização de mecanismos de integração regionais como Mercosul, Unasul e IIRSA, apontam para a importância estratégica do Brasil se firmar como liderança regional. É neste contexto globalizado, onde as grandes corporações possuem peso significativo que passamos a investigar as atividades da Petrobras como peça chave do desenvolvimento brasileiro.

De uma maneira geral, os dados apresentados e a literatura sobre o tema demonstram um otimismo crescente em relação às atividades da estatal e do Brasil no processo de integração regional. No entanto, verificamos que a literatura carece ainda, de análises mais aprofundadas e críticas sobre temáticas emergentes na esferas doméstica e regional, tais como os impactos sócio espaciais e as transformações na qualificação da mão de obra advindos da construção e integração da infraestrutura energética brasileira e sul-americana; as modificações na participação política de municípios e estados frente aos royalties do petróleo; a modernização de instituições 
públicas de ensino e pesquisa; os novos fomentos à cultura; a formação de uma nova classe de produtores simbólicos e seus impactos no mercado imobiliário; as novas segmentação sócio espacial, entre tantos outros temas.

\section{Notas}

1. OPEC. Brief History. Disponível em: www.opec.org/opec_web/en/about_us/24.htm. Acesso em 06 de Janeiro de 2012.

2. Em matéria ñPetrobras aposta em refinarias no exteriorò da edição de domingo do dia 18/10/2009, em O Globo, o diretor da Área Internacional da Petrobrás, Jorge Luiz Zelada, fala em entrevista sobre os investimentos da Petrobras no exterior, sob o contexto nacional do pré-sal.

3. Petrobrás. Plano de Negócios 2007-2011.Disponível em: www.petrobras.com.br. Acesso em 06 de Janeiro de 2012.

4. Segundo estudos realizados sobre as reservas do energético boliviano pela empresa americana Ryder Scott, por solicitação do governo Evo Morales e anunciados em 06/08/2010, a reserva provada de gás da Bolívia é pelo menos de 19 trilhões de pés cúbicos, o que permite abastecer a demanda externa e interna nos próximos 20 anos. Atualmente a Bolívia exporta 30 milhões de metros cúbicos diários de gás ao Brasil e pouco mais de sete milhões para a Argentina, que são seus únicos mercados externos, embora esteja negociando novos acordos e contratos com Uruguai e Paraguai. O estudo indicou ainda que a Bolívia possui a segunda reserva de gás provada da América do Sul depois da Venezuela.

5. Informações da Transportadora Brasileira Gasoduto Bolívia-Brasil S.A. (TBG). Disponível em: www.tbg.com.br. Acesso em 12 de Dezembro de 2011.

6. Petrobras Bolívia, responsável por todos os negócios da Companhia na Bolívia, constitui-se em uma unidade autônoma vinculada à Gerência Executiva para o Cone Sul. A estrutura da Petrobras Bolívia é formada por três empresas, e cada uma compõe uma Sociedade Anônima. Petrobras Bolívia Inversiones y Servicios S.A. (PEBIS), holding que concentra as participações acionárias e o controle, além de prover serviços às demais empresas que integram a Petrobras Bolívia. Petrobras Bolívia S.A. (PEB), responsável pelas operações de exploração, produção e comercialização de hidrocarbonetos. Petrobras Bolívia Transportes S.A. (PBT), proprietária e operadora do gasoduto GASAM, que se estende desde o GASBOL (Gasoduto Bolívia-Brasil) até a linha de fronteira entre os dois países. Já a Transierra, a Petrobras Bolívia possui participação societária, responde pela operação do gasoduto Yacuiba-Río Grande (GASYRG), de 432Km de comprimento. (http://www.petrobras.com/pt/paises/bolivia/bolivia.htm)

7. http://www.petrobras.com/pt/paises/bolivia/bolivia.htm

8. A construção do gasoduto Bolívia-Brasil foi financiada pela Petrobras em US\$1,58 bilhão para o trecho brasileiro e cerca de US\$ 435 milhões para o trecho boliviano. Em 1999 foi instalado o último duto possibilitando, então, o início do fornecimento de gás boliviano ao Brasil.

9. O Informe Mercosul 2000-2001 utiliza o ano base 1998.

10. Dados disponíveis em: http://data.worldbank.org/indicator/NY.GDP.MKTP.CD/countries.

\section{Referências}

AL-NAIMI, Ali I. Saudi Arabia oil and gas investiment outlook and strategies. In: Third OPEC Internacional seminar, Viena, Sep 2006. Disponível em: 
http://www.opec.org/opec_web/en/.BAER, Werner. A economia brasileira. 2 ed. São Paulo: Nobel, 2002.

DESLANDES, Ligia Arneiro Teixeira. As lutas pós-coloniais dos trabalhadores do petróleo. a construção dos saberes, poderes e práticas no cotidiano sindical. Tomo I, São Paulo: biblioteca24horas, 2011.

FUSER, Igor. Internacionalização e conflito: a Petrobras na América do Sul. In: ENCONTRO NACIONAL DE ECONOMIA POLÍTICA. 12, 2007, São Paulo. Disponível em: <http://www.sep.org.br/artigo/888_314e9e118b3026ce64b768b84a22d 816.pdf?PHPSESSID=93c69bf512f15aacfd4cac3a9c $>$. Acesso em: 10 de outubro de 2011.

GABRIELLI DE AZEVEDO, José Sérgio. Esboço de marco conceitual para análise da indústria do petróleo, pré-sal e desenvolvimento. In: GAMBIAGI, Fábio; BARROS, Octavio de (Orgs). Brasill pós-crise: agenda para a próxima década. Rio de Janeiro: Elsevier, 2009. p. 247-264.

HARVEY, David. O novo imperialismo. 2 ed. São Paulo: Edições Loyola, 2005.

HOFMEISTER, Wilhelm. No obediencia, pero mayor interdependência: la relación del Brasil con sus vecinos. In: COSTA, Sérgio; SANGMEISTER, Harmut; STECKBAUER, Sonja (Orgs). O Brasil na América Latina: interações, percepções, interdependências. São Paulo: Annablume, 2007. p. 65-90.

HOYOS, Carola. The new seven sisters: oil and gas giants dwarf western rivals. FT.com, 2007. Disponível em: http://www.ft.com/int1/cms/s/2/471ae1b8-d001-11db94cb-000b5df10621.html\#axzz1izEA6vKz. Acesso em: 04 de Janeiro de 2012.

INFORME Mercosul, Ano 6, n. 7. BID-INTAL - Periodo 2000-2001. TACONNE, Juan José; NOGUEIRA, Uziel (Editores). Buenos Aires. 2001

LIMA, Maria Regina Soares; COUTINHO, Marcelo Vasconcelos. Uma versão estrutural do regionalismo. In: DINIZ, Eli (Org.). Globalização, estado e desenvolvimento: dilemas do Brasil no novo milênio. Rio de Janeiro: Editora FGV, 2007. p.125-154.

PENNA, Lincoln de Abreu. Caminhos da soberania nacional. os comunistas e a criação da Petrobras. 1 ed. Rio de Janeiro: E-Papers Serviços Editoriais Ltda., 2005.

PETROBRAS. Disponível em: www.petrobras.com.br

PIQUET, Rosélia, SERRA, Rodrigo. Petróleo e região no Brasil. O desafio da abundância. PIQUET, Rosélia; SERRA, Rodrigo (Orgs). Rio de Janeiro: Garamond Universitária, 2007.

PLANO DE NEGÓCIOS DA PETROBRAS 2006-2010. Disponível em: www.cogen.com.br/workshop/2005/Pl Neg Petrobras 2006 2010 Fiesp.pdf 
PLANO DE NEGÓCIOS DA PETROBRAS 2007-2011. Disponível em: www.petrobras.com.br/ri/Show.aspx?id_materia=B4xQDpB9gtc+60BpfzvImg==;

PLANO DE NEGÓCIOS DA PETROBRAS 2010-2014. Disponível em: www.petrobras.com.br/ri/Show.aspx?id_materia=4PGQYDVxrU544HYs+8WYHQ

REVISTA América Econômica, 500 Maiores Empresas da América Latina, julho 2010.

SANTOS, Edmilson Moutinho dos. Gás natural estratégias para uma energia nova no Brasil. São Paulo: annablumme, FAPESP, PETROBRAS, 2002.

SENA FILHO, Nelson. A geopolítica do Petróleo. In: PENNA, Lincoln de Abreu, SENA FILHO, Nelson; SOUZA, Celeste Aparecida Dias (Orgs). Petróleo no Brasil. Três ensaios sobre a Petrobrás. Rio de Janeiro: E-Papers Serviços Editoriais, 2004. p. 59-88.

SIMÕES, Antonio José F. Sonho e realidade na América do Sul. Disponível em: www1.folha.uol.com.br/fsp/opiniao/fz1105201008.htm. Acesso em 12 de Dezembro de 2011.

ZAMITH, Regina. A indústria para-petroleira nacional. São Paulo: Annablume, 2001.

ZELADA, Jorge Luiz. Petrobrás aposta em refinaria no exterior. O Globo, 18/10/2009. Disponível em: http://fatosedados.blogspetrobras.com.br/2009/10/18/. 